\title{
A multi-laboratory profile of Mycoplasma contamination in Lawsonia intracellularis cultures
}

Jeong-Min Hwang ${ }^{1 \dagger}$, Ji-Hye Lee ${ }^{2+}$ and Jung-Yong Yeh ${ }^{2 *}$

\begin{abstract}
Background: During the routine laboratory cultivation of Lawsonia intracellularis, Mycoplasma contamination has been a frequent problem. When Mycoplasma contamination occurs in laboratories that study L. intracellularis, the cultures must be discarded for 4 reasons: 1) Mycoplasma is inevitably concentrated along with L. intracellularis during the passage of L. intracellularis; 2) Mycoplasma inhibits the growth of L. intracellularis; and 3 ) it is impossible to selectively eliminate Mycoplasma in L. intracellularis cultures. In this study, we observed the contamination of Mycoplasma species during $L$. intracellularis cultivation among multiple laboratories.

Results: The presence of a Mycoplasma infection in the L. intracellularis cultures was verified using polymerase chain reaction (PCR), and a sequence analysis of the partial 165 rRNA and 235 rRNA genes was performed. A PCRbased assay using genus-specific universal primers revealed that $29(85.3 \%)$ of the 34 cultures were contaminated with Mycoplasma, including 26 with M. hyorhinis (89.2\%), 2 with M. orale (6.9\%), and 1 with M. fermentans (3.4\%). The Mycoplasma contamination was not the result of infection with material of pig origin. McCoy cells, which are required for the cultivation of $L$. intracellularis, were also ruled out as the source of the Mycoplasma contamination.

Conclusions: In this study, M. hyorhinis was identified as the most common mollicute that contaminated $L$. intracellularis cultures. Whether L. intracellularis enhances the biological properties of Mycoplasma to promote infection in McCoy cells is not known. Because the McCoy cell line stocks that were used simultaneously were all negative for Mycoplasma, and the same worker handled both the McCoy cells to maintain the bacteria and the $L$. intracellularis cultures, it is possible that the L. intracellularis cultures are more vulnerable to Mycoplasma contamination. Taken together, these results suggest that continuous cultures of $L$. intracellularis must be tested for Mycoplasma contamination at regular intervals.

The GenBank accession numbers for the sequences reported in this paper are JN689375 to JN689377.
\end{abstract}

\section{Background}

Mycoplasmas, which are bacteria that lack a cell wall and belong to the class Mollicutes, are found in the physiological flora of both humans and animals, can act as opportunistic pathogens, and are frequent contaminants of cell cultures. Because they frequently contaminate both primary and stable cell lines, species of the genera Mycoplasma and Acholeplasma are a major concern with regard to the regulatory aspects of biosafety [1-6]. Mycoplasma contamination affects many aspects of cell culture, which can lead to unreliable experimental

\footnotetext{
* Correspondence: malvab2848@gmail.com

+ Contributed equally

${ }^{2}$ Foreign Animal Diseases Division, Animal, Plant, and Fisheries Quarantine and Inspection Agency, Anyang-ro 175, Manan-gu, Anyang-si, Gyeonggi-do 430-824, Republic of Korea

Full list of author information is available at the end of the article
}

results and potentially harmful biological products $[7,8]$. Undetected mycoplasmas can persist in a culture because unlike other bacteria and fungi, mollicute contaminants do not result in turbid growth or cause cell damage [9]. Moreover, the majority of mollicutes are resistant to the antibiotics that are commonly used in long-term cell cultures [10]. Of the 20 mollicute species that are known to cause cell culture contamination, 5 (M. arginini, $M$. fermentans, $M$. hyorhinis, $M$. orale, and A laidlawii) account for approximately $95 \%$ of contamination cases [11,12].

Lawsonia intracellularis is a highly fastidious, obligate intracellular, Gram-negative bacterium and is a relatively newly identified member of the Desulfovibrionaceae family [13]. L. intracellularis is one of the most prevalent enteric pathogens in pigs, where it causes acute 
intestinal hemorrhaging (proliferative hemorrhagic enteropathy, or PHE) in naïve adult pigs and a wasting disease (porcine intestinal adenomatosis, or PIA) in growing pigs [14]. The in vitro culture of L. intracellularis is only possible when the bacterium is co-cultivated with a range of cell lines $[15,16]$. Currently, most researchers prefer to use McCoy mouse fibroblast cells for the isolation and maintenance of $L$. intracellularis in vitro [17-23].

Cell culture has become an indispensable tool for studying proliferative enteropathy in horses and pigs; however, during the routine cultivation of $L$. intracellularis in the authors' laboratories, Mycoplasma contamination has been a serious and frequent problem. One widely used method to passage $L$. intracellularis cultures involves concentrating the bacteria that are extracted from infected cell monolayers $[16,24]$. One caveat to this method is that it has the potential to concentrate mycoplasmal agents in addition to L. intracellularis, and Mycoplasma contamination may have already occurred at the start of the L. intracellularis culture. It is inevitable that Mycoplasma is concentrated along with $L$. intracellularis during this culture process. We observed that Mycoplasma inhibited the growth of L. intracellularis, which was then eventually lost from the culture. If Mycoplasma contamination of L. intracellularis cultures occurs during cell culture maintenance, these cultures must be discarded because the selective elimination of Mycoplasma from L. intracellularis cultures is not possible.

In the Republic of Korea (RO Korea), 5 laboratories handling L. intracellularis have encountered Mycoplasma contamination during the process of maintaining this bacterium. Mycoplasma contamination is one of the most critical factors that determines the success of $L$. intracellularis cultivation and has remained one of the biggest obstacles in isolating L. intracellularis. However, previous studies have not examined this contamination issue; therefore, we describe here the profiles of bacterial contamination with various Mycoplasma species in cells that are used during L. intracellularis cultivation in multiple laboratories.

\section{Methods}

\section{Isolates and laboratories}

The isolates from each laboratory were originally derived from two low-passage-number clinical isolates. First, the PHE/KK421 strain of L. intracellularis was isolated from a finisher pig with acute PHE in 2002 [23], and the second strain (PIA/MyCoyL1), was isolated from a grower pig with PIA in 2010 [25]. Contamination was not observed in either the McCoy cells that were used to maintain L. intracellularis or in L. intracellularis cultures, which were distributed to each laboratory, at passage numbers 1 through 10 . The isolates were maintained by different researchers in each of the 5 laboratories, which were all located in the RO Korea. The laboratories were not linked; each laboratory independently maintained its own isolate (PHE/KK421 and/or PIA/MyCoyL1). The specimens used in this study were collected from cultures that had been maintained by different laboratory workers in different laboratories.

\section{Test samples and DNA isolation}

The test samples were chosen based on the fact that they were independently handled by different workers and were stored at different times. These samples were collected from L. intracellularis cultures that were not subjected to normal maintenance procedures because of suspected Mycoplasma contamination. Aliquots of frozen stocks from 2 or 3 passages of each culture were screened for the presence of mollicutes. The Mycoplasma contamination status of $34 \mathrm{~L}$. intracellularis culture stocks was analyzed using polymerase chain reaction (PCR). Mycoplasma PCR testing was performed at the Animal, Plant, and Fisheries Quarantine and Inspection Agency in Anyang-si, RO Korea. Briefly, 500- $\mu \mathrm{l}$ aliquots of the $L$. intracellularis culture stocks were placed in microcentrifuge tubes for PCR analysis. These aliquots were concentrated via centrifugation at $13,000 \times g$ for $10 \mathrm{~min}$ at room temperature followed by the removal of $480 \mu \mathrm{l}$ of the medium and the addition of $380 \mu \mathrm{l}$ of sterile water to the remaining $20 \mu \mathrm{l}$ of the medium and the pellet. The resulting supernatants were discarded, and the pellets were washed twice with phosphate-buffered saline (PBS). After the second wash, the pellets were resuspended in $400 \mu \mathrm{l}$ of PBS and were incubated for $15 \mathrm{~min}$ at $95^{\circ} \mathrm{C}$. An automated DNA extraction was performed using a BioRobot M48 workstation apparatus (Qiagen, GmbH, Hilden, Germany) with a MagAttract Virus Mini M48 kit (Qiagen). Nucleic acids were recovered in $50 \mu \mathrm{l}$ of the elution buffer. The eluted genomic DNA was stored at $-70^{\circ} \mathrm{C}$ until use. The McCoy cell line stocks that were used simultaneously were also tested to determine whether the McCoy cells were the source of the Mycoplasma contamination.

\section{Mycoplasma PCR testing}

To detect Mycoplasma DNA and to identify the contaminating Mycoplasma spp., 15 primers were used to amplify a conserved spacer region that encompasses the $16 \mathrm{~S}$ and $23 \mathrm{~S}$ rRNA genes as previously described (Table 1). Mycoplasma genus-specific PCR analysis was performed with a total reaction mixture volume of 20 $\mu \mathrm{l}$. The 16S-23S rRNA regions of all mollicutes species that were used in the study were amplified using multiple primer sets under each PCR condition. The PCR 
conditions and oligonucleotide primers that were used to amplify the nucleic acids are shown in Table 1 . The reactions were prepared in a volume of $25 \mu \mathrm{l}$ that contained $2 \mu \mathrm{l}$ of DNA, $1 \mathrm{U}$ of Taq DNA polymerase, 250 $\mu \mathrm{mol} / \mathrm{l}$ of each dNTP, $50 \mathrm{mmol} / \mathrm{l}$ of Tris- $\mathrm{HCl}(\mathrm{pH} 8.3)$, 40 of mmol/l KCl, $1.5 \mathrm{mmol} / \mathrm{l}$ of $\mathrm{MgCl}_{2}$, gel loading dye, and 5 pmol of each primer set using a PCR master mix (AccuPower PCR PreMix, Bioneer Corp., Daejeon, RO Korea). To prevent amplicon contamination, aerosol-barrier tips were used. The reagent mixtures were prepared in a limited-access PCR clean room, were moved to a sample preparation room for the addition of cell lysates, and were finally moved to a PCR instrumentation room for amplification. The PCR amplifications were performed using an Eppendorf Mastercycler gradient thermal cycler (Eppendorf, Hamburg, Germany). A negative control with no template was also included. Thirteen strains of Mycoplasma were obtained from the American Type Culture Collection (ATCC, Edinburg, VA, US) for use as positive controls. These strains included M. arthritidis ATCC 13988, M. bovis ATCC 25025, M. fermentans ATCC 19989, M. genitalium ATCC 33530, M. hominis ATCC 23114, M. hyorhinis ATCC 17981, M. neurolyticum ATCC 15049 , M. orale ATCC 23714, M. pirum ATCC 25960, M. pneumoniae ATCC 15531, M. pulmonis ATCC 23115, M. salivarium ATCC 23064, and Ureaplasma urealyticum ATCC 27618. The amplified products were analyzed on a $1.5 \%$ agarose gel containing $0.5 \mu \mathrm{g} / \mathrm{ml}$ ethidium bromide and were visualized at the maximum levels of intensity using a Gel Doc 1000 gel analysis system (Bio-Rad Laboratories, Hercules, CA, USA).

\section{Sequencing of PCR products}

The PCR products of the Mycoplasma spp. from the contaminated $L$. intracellularis cultures were purified using the ExoSAP-IT reagent (USB Corporation, Cleveland, OH, USA) to remove any unwanted deoxynucleoside triphosphates and primers from the PCR product mixture. A 2- $\mu \mathrm{l}$ aliquot of the clean PCR products was analyzed for purity and concentration on a $1 \%$ agarose gel, and then the remaining sample was cloned into the pGEM-T Easy Vector System I (Promega, Madison, WI, USA). We verified that the clones contained inserts by digesting the plasmid DNA with EcoRI (New England Biolabs, Hitchin, Hertfordshire, UK) and by separating the plasmid fragments on a $1.5 \%$ agarose gel. Sequencing analysis was performed by Macrogen, Inc. (Seoul, RO Korea). All of the sequences were identified using the BLAST search engine (http://blast.ncbi.nlm.nih.gov/ Blast.cgi).

\section{Mycoplasma enrichment culture}

To determine if Mycoplasma might be present with a titer below the detection limit of the PCR assays and to rule out the possibility of a false negative result, the samples were taken into culture and tested again over several passages. To enrich any Mycoplasma that might be present, the culture supernatant was incubated at $37^{\circ}$ $\mathrm{C}$ in a controlled environment using pleuropneumonialike organisms (PPLO) media, PPLO broth $(21 \mathrm{~g} / \mathrm{l}$; Difco, Sparks, MD, USA), or PPLO agar (35 g/l; Difco), which consisted of $100 \mathrm{ml} / \mathrm{l}$ (25\%) Baker's extract solution, $200 \mathrm{ml} / \mathrm{l}$ horse serum (Cambrex, USA), $2 \mathrm{ml} / \mathrm{l}$ (1\%) phenol red (Sigma, USA), $5 \mathrm{ml} / \mathrm{l}(2.5 \%)$ thallium acetate

Table 1 PCR primer sequences

\begin{tabular}{|c|c|c|c|}
\hline Target gene & Primer & Nucleotide sequence $\left(5^{\prime} \rightarrow 3^{\prime}\right)^{a}$ & Reference \\
\hline \multirow[t]{9}{*}{$16 \mathrm{~S}$ rRNA } & MyU 5-1 & CGCCTGAGTAGTACGTTCGC & {$[26]$} \\
\hline & MyU 5-2 & CGCCTGAGTAGTACGTACGC & \\
\hline & MyU 5-3 & TGCCTGAGTAGTACATTCGC & \\
\hline & MyU 5-4 & TGCCTGGGTAGTACATTCGC & \\
\hline & MyU 5-5 & CGCCTGGGTAGTACATTCGC & \\
\hline & MyU 5-6 & CGCCTGAGTAGTATGCTCGC & \\
\hline & MyU 3-1 ${ }^{b}$ & GCGGTGTGTACAAGACCCGA & \\
\hline & $M y \cup 3-2^{b}$ & GCGGTGTGTACAAAACCCGA & \\
\hline & $M y \cup 3-3^{b}$ & GCGGTGTGTACAAACCCCGA & \\
\hline \multirow[t]{6}{*}{$16 \mathrm{~S}$ and $23 \mathrm{~S}$ rRNA } & F1 (OF) & ACACCATGGGAGYTGGTAAT & {$[27]$} \\
\hline & $\mathrm{R}^{\mathrm{b}}(\mathrm{OF})$ & CTTCWTCGACTTYCAGACCCAAGGCAT & \\
\hline & FN2 (IF) & ACCTCCTITCTACGGAGTACAA & \\
\hline & $\mathrm{R} 2^{\mathrm{b}}(\mathrm{IR}$ & GCATCCACCAWAWACYCTT & \\
\hline & FN3 (IF) & TATTTGCTATTCAGTITCAAAGAAC & \\
\hline & $\mathrm{RN}^{\mathrm{b}}(\mathrm{IR})$ & GGGGTGAAGTCGTAACAAGGTAT & \\
\hline
\end{tabular}

\footnotetext{
${ }^{a}$ Abbreviations represent a mixed-base code, which was used to reduce the number of primers. $Y=C, T$ and $W=A, T$
}

${ }^{b}$ Primers are in the reverse orientation 
(Sigma), $10 \mathrm{ml} / \mathrm{l}$ (106 U/l) penicillin G (Sigma), and a carbon source (either $10 \mathrm{~g} / \mathrm{l}$ glucose, $2 \mathrm{~g} / \mathrm{l}$ arginine, or $0.4 \mathrm{~g} / \mathrm{l}$ urea). Either an anaerobic jar or a $\mathrm{CO}_{2}$ incubator was used for these experiments. Because bacterial metabolism leads to a $\mathrm{pH}$ shift, a sequential color change of the PPLO medium from results, going from red to orange and then to yellow. When the color change indicated that the bacteria were metabolically active, the culture solutions were plated onto PPLO agar plates. Colonies were evaluated by inverted microscopy every week for 2-3 weeks to determine the number of colony-forming units (CFU) and to monitor the development of typical colonies (a fried-egg appearance). Mycoplasma culture solutions were stored at $-70^{\circ} \mathrm{C}$.

\section{Investigation of indicator cell lines}

Culture supernatants were transferred to a Mycoplasma negative indicator cell line such as Mardin-Darby Bovine Kidney (MDBK) and Vero and tested after a culturing period. Parallel cultures without supernatant were cultured concurrently as a negative control.

\section{Results}

The contaminated cultures in this study had been produced between 2002 and 2010 in 5 different research laboratories that handled $L$. intracellularis. Aliquots from 29 of the $34(85.3 \%)$ L. intracellularis cultures that contained an unidentified contaminant tested positive for Mycoplasma DNA (Table 2). The contaminant in the remaining 5 cultures remained unidentified because it was not amplified by the Mycoplasma PCR assay that was employed in this study. The results of each PCR assay were identical. To identify the Mycoplasma spp. in the contaminated cell culture samples, Mycoplasma DNA amplicons from selected positive cultures were sequenced and compared with the GenBank database and the database of the National Center for Biotechnology Information (NCBI, Bethesda, MD, USA). The majority of the L. intracellularis cultures with unidentified contamination were chronically infected with $\mathrm{Myco-}$ plasma. A total of $26 \mathrm{~L}$. intracellularis cultures contained DNA sequences that matched those of $M$. hyorhinis (100\% sequence identity), whereas 2 cultures and 1 culture contained DNA sequences that matched those of $M$. orale and $M$. fermentans, respectively (100\% sequence identity). Each culture was infected with only a single species of mollicute. The stock specimens were deposited at intervals of 2 or 3 passages for each culture. The McCoy cell line stocks that were used simultaneously were all negative for Mycoplasma. These results suggest that McCoy cells, which are required for the cultivation of $L$. intracellularis, were not the source of the Mycoplasma contamination. The $M$. orale, M. fermentans, and M. hyorhinis $16 \mathrm{~S}$ and 23S rRNA sequences that were determined in this study have been deposited in the GenBank database under accession numbers JN689375 to JN689377. When the supernatant from the Mycoplasma-contaminated Lawsonia cultures was transferred to a Mycoplasma-negative indicator cell line (MDBK and Vero) and tested after an appropriate culture period, the indicator cell lines were infected with the same Mycoplasma species that were involved in the L. intracellularis infections. All parallel cultures that did not contain supernatant were Mycoplasma negative, and all of the PCR-negative samples were also confirmed to be negative when they were cultured and retested over the course of several passages.

Table 2 Mollicute strains identified in the L.intracellularis stock specimens

\begin{tabular}{|c|c|c|c|c|c|c|c|}
\hline \multirow[t]{2}{*}{ Laboratory $^{\mathrm{a}}$} & \multirow[t]{2}{*}{$\begin{array}{l}\text { Period stocked } \\
\text { (years) }\end{array}$} & \multirow[t]{2}{*}{$\begin{array}{l}\text { Isolate used }{ }^{\mathrm{b}} \text { (no. of } \\
\text { passages, range) }\end{array}$} & \multirow[t]{2}{*}{$\begin{array}{l}\text { \# of Tested } \\
\text { Cultures }\end{array}$} & \multirow[t]{2}{*}{$\begin{array}{l}\text { \# of Mycoplasma- } \\
\text { Contaminated }\end{array}$} & \multicolumn{3}{|c|}{$\begin{array}{l}\text { Mycoplasma Spp. } \\
\text { Identification (\#) }\end{array}$} \\
\hline & & & & & $\begin{array}{l}\text { M. } \\
\text { fermentans }\end{array}$ & $\begin{array}{l}\text { M. } \\
\text { hyorhinis }\end{array}$ & $\begin{array}{l}\text { M. } \\
\text { orale }\end{array}$ \\
\hline KKU & $2002-2004$ & KK421 (20-30) & 3 & 3 & & 3 & \\
\hline NIAST & 2004-2005 & KK421 (20-30) & 4 & 4 & & 4 & \\
\hline NVRQS TSE & 2005-2006 & KK421 (40-70) & 13 & 11 & 1 & 9 & 1 \\
\hline QIA EID & 2006-2011 & $\begin{array}{l}\text { KK421 (20-30) and MyCoyL1 } \\
(10-20)\end{array}$ & 9 & 8 & & 7 & 1 \\
\hline GC & 2004-2011 & $\begin{array}{l}\text { KK421 (40-50) and MyCoyL1 } \\
(10-20)\end{array}$ & 5 & 3 & & 3 & \\
\hline \multicolumn{3}{|l|}{ Total } & $34^{c}$ & 29 & 1 & 26 & 2 \\
\hline
\end{tabular}




\section{Discussion}

Mollicute strains, including Mycoplasma, are widespread human, animal, and plant parasites [3]. In this study, the majority of the Mycoplasma contaminants in L. intracellularis cultures were of the species $M$. hyorhinis, which is one of the most commonly identified contaminating Mycoplasma species in laboratory cell culture [28,29], although it is a porcine respiratory parasite and is rarely found in human subjects. Routine screenings have now been conducted on a regular basis since this study was initiated in laboratories employed in this study. Chronic contamination with $M$. hyorhinis was detected in several cases, which resulted in the loss of the contaminated $L$. intracellularis cultures. Transient Mycoplasma contamination of $L$. intracellularis cultures was also detected in several cases during the Mycoplasma screening effort. Although these L. intracellularis cultures were maintained normally, and no cytopathic effects were seen in the McCoy cells, we confirmed that these cultures were indeed positive for Mycoplasma DNA. These cultures were defined as transiently contaminated because the infection no longer remained after two or three passages following the initial detection of $M$. fermentans or $M$. orale DNA. These transient contaminations were detected by both of the PCR assays that were used in this study and lasted for one to two weeks, after which the cultures remained negative for Mycoplasma DNA over several passages. In addition, to rule out possibility of DNA contamination from the laboratory setting that could result in both false positives and false negatives, we performed another completely independent and sensitive Mycoplasma detection assay using MycoAlert (Cambrex, USA). The results of this assay confirmed those of the PCR testing. The transient contaminations were found to occur in two of the three laboratories that were involved in this study, and the transiently contaminated Mycoplasma spp. in those two labs were identified to be $M$. orale and $M$. fermentans instead of $M$. hyorhinis. We observed that the M. hyorhinis (26), $M$. orale (2), and $M$. fermentans (1) contaminations that are listed in Table 2 were persistent in all detected cases. When we assessed the persistence and transience of these Mycoplasma spp., M. hyorhinis contaminations were persistent in all detected cases, while $M$. orale and M. fermentans were transient in half of the initially detected cases. These finding suggest that L. intracellularis cultures might be more vulnerable to long-term $M$. hyorhinis contamination, while contamination with $M$. orale and $M$. fermentans might be shorter lasting. To our knowledge, no transient Mycoplasma contaminations of cell cultures have been described thus far, although Lemoine et al. (1987) previously reported that Mycoplasma contamination during pregnancy appears to be very transient and has no effect on the immediate neonatal pathology [30].

These results support the idea that Mycoplasma contamination is common in L. intracellularis cultures and/ or in the cell lines that are used to grow this bacterium. However, whether L. intracellularis enhances the biological properties of Mycoplasma to promote its infection of McCoy cells remains unclear. Because the McCoy cell line stocks that were used simultaneously were all negative for Mycoplasma contamination and the same worker handled both the McCoy cells and the L. intracellularis cultures, it appears that the L. intracellularis cultures may be more vulnerable to Mycoplasma contamination. In other words, if the person who handled both sets of cells was infected with Mycoplasma, this suggests that the L. intracellularis cultures were more vulnerable to Mycoplasma contamination for the following reasons: a) the Mycoplasma contamination did not stem from the original McCoy cell line; b) the L. intracellularis cultures were Mycoplasma-free for their first 10 passages prior to their distribution to each laboratory; c) handling the McCoy cell lines and the L. intracellularis was performed separately but by the same person. In other words, the Mycoplasma contamination was most likely introduced by the persons who handled both the McCoy cells and the L. intracellularis bacterial cultures; d) although it is a common problem in instances of mycoplasmal contamination, any cross-contamination of other cell lines, equipment, media, reagents, etc. in the laboratories could be ruled out because separate reagent containers were used in all cases (including bacterial cultures, McCoy cell cultures, and other cell lines); and e) to reduce cross-contamination in the laboratory setting, equipment was not shared by the bacterial and cell cultures. However, further studies are needed to determine the specific factors that are involved in the establishment of transient and chronic Mycoplasma contamination in L. intracellularis cultures.

Mycoplasmas are likely to be acquired by a host through intimate contact that results in the transfer of material between mucosal surfaces [31]; therefore, we cannot rule out the possibility that laboratory workers may be sources of Mycoplasma contamination in the cell cultures that they maintain. We do not believe that the contamination observed in this study occurred because of the use of contaminated cell lines or the presence of Mycoplasma spp. in the original specimens because we confirmed that the $L$. intracellularis culture were Mycoplasma-free for their first 10 passages before being distributed to each laboratory. Cross-contamination between the laboratories that participated in the present study can also be excluded because the 
laboratories were not linked and each laboratory independently grew and maintained its own isolate (PHE/ KK421 or/and PIA/MyCoyL1), as described in the Materials and Methods. Taken together, these observations imply that the initial Mycoplasma contamination originated from human handling. These results suggest that continuous cultures of $L$. intracellularis must be tested for Mycoplasma contamination at regular intervals.

In the case of other intracellular bacteria, KrausseOpatz et al. found that $M$. fermentans, M. hyorhinis, and M. hominis were present as contaminating agents [32]. Huniche et al. reported that 3 of 6 Chlamydia pneumoniae isolates from ATCC along with two Finnish isolates of that bacterium were infected with $M$. hominis and $M$. orale [33]. Although $M$. hyorhinis was found the most frequently in L. intracellularis cultures in this study, $M$. hominis has been more frequently reported in Chlamydia cultures in previous publications. Messmer et al. has also suggested that intracellular bacteria such as Chlamydia should be periodically screened for Mycoplasma contamination [34]. Careful attention is important in research that involves intracellular bacteria because Mycoplasma contamination could pose a serious problem for this kind of experiments.

\section{Conclusions}

In this study, M. hyorhinis was identified as the most common mollicute that contaminated L. intracellularis cultures; however, it is still unclear whether L. intracellularis enhances the biological properties of $\mathrm{Myco-}$ plasma to promote the infection of the McCoy cells. Because the McCoy cell line stocks that were used simultaneously were all negative for Mycoplasma, and the same worker handled both the McCoy cells and the L. intracellularis cultures, this suggests that $L$. intracellularis cultures may be more vulnerable to Mycoplasma contamination. Taken together, these results suggest that continuous cultures of $L$. intracellularis must be tested for Mycoplasma contamination at regular intervals.

\section{Abbreviations}

PHE: Proliferative hemorrhagic enteropathy; PIA: Porcine intestinal adenomatosis; RO Korea: Republic of Korea; PCR: Polymerase chain reaction; PBS: Phosphate-buffered saline.

\footnotetext{
Acknowledgements

This work was supported by the Animal, Plant, and Fisheries Quarantine and Inspection Agency, RO Korea (grant \#: 6235-320-210-13). The authors would like to thank Hyung-Seok Lee, Hee-Soo Park, Mi-Ran Choi, Jin-Hwa Lee, MinAe Ahn and Su-Mi Lee at the Animal, Plant, and Fisheries Quarantine and Inspection Agency, RO Korea, for all of their help with the experimental work. The authors also thank two anonymous reviewers for helpful comments on preliminary drafts.
}

\section{Author details}

${ }^{1}$ Veterinary Research Center, Green Cross Veterinary Products Co., Ltd., 227-5, Kugal-dong, Giheung-gu, Yongin-si, Gyeonggi-do 446-903, Republic of Korea. ${ }^{2}$ Foreign Animal Diseases Division, Animal, Plant, and Fisheries Quarantine and Inspection Agency, Anyang-ro 175, Manan-gu, Anyang-si, Gyeonggi-do 430-824, Republic of Korea.

\section{Authors' contributions}

JYY conceived of the study, designed the experiments, wrote the manuscript, and finalized the manuscript. JMH and JHL conducted the majority of the experiments including the cultivation of $L$. intracellularis and McCoy cells, mycoplasma PCR, and sequencing analysis. All authors read and approved the final manuscript.

\section{Competing interests}

The authors declare that they have no competing interests.

Received: 7 September 2011 Accepted: 27 January 2012

Published: 27 January 2012

\section{References}

1. Uphoff CC, Drexler HG: Detection of mycoplasma contaminations. Methods Mol Biol 2005, 290:13-23.

2. Uphoff CC, Drexler HG: Detection of mycoplasma contaminations in cell cultures by PCR analysis. Hum Cell 1999, 12(4):229-236.

3. Razin S, Yogev D, Naot Y: Molecular biology and pathogenicity of mycoplasmas. Microbiol Mol Biol Rev 1998, 62(4):1094-1156.

4. Razin S, Freundt EA: Bergey's manual of systematic bacteriolog. In The mycoplasma.. 1 edition. Edited by: Krieg NR, Holt JG. Baltimore, MD: Williams 1984:740-775.

5. Jules Mattes M: Control of the mycoplasma epidemic. In Vitro Cell Dev Biol Anim 2004, 40(8-9):253-254.

6. Drexler HG, Uphoff CC, Dirks WG, MacLeod RA: Mix-ups and mycoplasma: the enemies within. Leuk Res 2002, 26(4):329-333.

7. Harasawa R, Mizusawa H, Nozawa K, Nakagawa T, Asada K, Kato I: Detection and tentative identification of dominant mycoplasma species in cell cultures by restriction analysis of the 16S-23S rRNA intergenic spacer regions. Res Microbiol 1993, 144(6):489-493.

8. Kong F, James G, Gordon S, Zelynski A, Gilbert GL: Species-specific PCR for identification of common contaminant mollicutes in cell culture. Appl Environ Microbiol 2001, 67(7):3195-3200.

9. Uphoff CC, Brauer S, Grunicke D, Gignac SM, MacLeod RA, Quentmeier H, Steube K, Tummler M, Voges M, Wagner B, et al: Sensitivity and specificity of five different mycoplasma detection assays. Leukemia 1992, 6(4):335-341

10. Rawadi G, Dussurget O: Advances in PCR-based detection of mycoplasmas contaminating cell cultures. PCR Methods Appl 1995, 4(4):199-208.

11. Tang J, Hu M, Lee S, Roblin R: A polymerase chain reaction based method for detecting Mycoplasma/Acholeplasma contaminants in cell culture. J Microbiol Methods 2000, 39(2):121-126.

12. Ossewaarde J, de Vries A, Bestebroer T, Angulo A: Application of a Mycoplasma group-specific PCR for monitoring decontamination of Mycoplasma-infected Chlamydia sp. strains. Appl Environ Microbiol 1996, 62(2):328-331.

13. McOrist S, Gebhart CJ, Boid R, Barns SM: Characterization of Lawsonia intracellularis gen. nov., sp. nov., the obligately intracellular bacterium of porcine proliferative enteropathy. Int J Syst Bacteriol 1995, 45(4):820-825.

14. Lawson GH, Gebhart CJ: Proliferative enteropathy. J Comp Pathol 2000, 122(2-3):77-100

15. Guedes RM, Gebhart CJ: Onset and duration of fecal shedding, cellmediated and humoral immune responses in pigs after challenge with a pathogenic isolate or attenuated vaccine strain of Lawsonia intracellularis. Vet Microbio/ 2003, 91(2-3):135-145.

16. Lawson GH, McOrist S, Jasni S, Mackie RA: Intracellular bacteria of porcine proliferative enteropathy: cultivation and maintenance in vitro. J Clin Microbiol 1993, 31(5):1136-1142.

17. Riber U, Boesen HT, Jakobsen JT, Nguyen LT, Jungersen G: Co-incubation with IL-18 potentiates antigen-specific IFN-gamma response in a wholeblood stimulation assay for measurement of cell-mediated immune 
responses in pigs experimentally infected with Lawsonia intracellularis. Vet Immunol Immunopathol 2011, 139(2-4):257-263.

18. Guedes RM, Gebhart CJ: Evidence of cell-mediated immune response and specific local mucosal immunoglobulin (lg) A production against Lawsonia intracellularis in experimentally infected swine. Can J Vet Res 2010, 74(2):97-101.

19. Pusterla N, Wattanaphansak S, Mapes S, Collier J, Hill J, Difrancesco M, Gebhart C: Oral infection of weanling foals with an equine isolate of Lawsonia intracellularis, agent of equine proliferative enteropathy. $J$ Vet Intern Med 2010, 24(3):622-627.

20. Oh YS, Lee JB, MCOrist S: Microarray analysis of differential expression of cell cycle and cell differentiation genes in cells infected with Lawsonia intracellularis. Vet J 2010, 184(3):340-345.

21. Wattanaphansak S, Singer RS, Isaacson RE, Deen J, Gramm BR, Gebhart CJ: In vitro assessment of the effectiveness of powder disinfectant (Stalosan F) against Lawsonia intracellularis using two different assays. Vet Microbiol 2009, 136(3-4):403-407.

22. Watarai M, Yoshiya M, Sato A, Furuoka H: Cultivation and characterization of Lawsonia intracellularis isolated from rabbit and pig. J Vet Med Sci 2008, 70(7):731-733.

23. Yeh JY, Kim TJ, Park SY, Song CS, Yoon YD, Kim SK, Lee JB, Choi IS: Isolation of Lawsonia intracellularis in Korea and reproduction of proliferative enteropathy in pigs and hamsters. J Vet Med Sci 2006, 68(5):499-501.

24. Guedes RM, Gebhart CJ: Comparison of intestinal mucosa homogenate and pure culture of the homologous Lawsonia intracellularis isolate in reproducing proliferative enteropathy in swine. Vet Microbiol 2003, 93(2):159-166

25. Yeh JY, Lee JH, Yeh HR, Kim A, Lee JY, Hwang JM, Kang BK, Kim JM, Choi IS, Lee JB: Antimicrobial susceptibility testing of two Lawsonia intracellularis isolates associated with proliferative hemorrhagic enteropathy and porcine intestinal adenomatosis in South Korea. Antimicrob Agents Chemother 2011, 55(9):4451-4453.

26. Uphoff CC, Drexler HG: Detection of mycoplasma in leukemia-lymphoma cell lines using polymerase chain reaction. Leukemia 2002, 16(2):289-293.

27. Sung H, Kang SH, Bae YJ, Hong JT, Chung YB, Lee CK, Song S: PCR-based detection of Mycoplasma species. J Microbiol 2006, 44(1):42-49.

28. Drexler HG, Uphoff CC: Mycoplasma contamination of cell cultures: incidence, sources, effects, detection, elimination, prevention. Cytotechnology 2002, 39(2):75-90.

29. Molla Kazemiha V, Shokrgozar MA, Arabestani MR, Shojaei Moghadam M, Azari S, Maleki S, Amanzadeh A, Jeddi Tehrani M, Shokri F: PCR-based detection and eradication of mycoplasmal infections from various mammalian cell lines: a local experience. Cytotechnology 2009, 61(3):117-124.

30. Lemoine JP, Buffet-Janvresse C, Duval C: Mycoplasmas and pregnancy. Rev Fr Gynecol Obstet 1987, 82(3):169-172.

31. Pitcher DG, Nicholas RA: Mycoplasma host specificity: fact or fiction? Vet J 2005, 170(3):300-306.

32. Krausse-Opatz B, Dollmann P, Zeidler H, Kuipers JG, Kohler L: Frequent contamination of Chlamydia trachomatis and Chlamydia pneumoniae strains with mycoplasma. biological relevance and selective eradication of mycoplasma from chlamydial cultures with mupirocin. Med Microbiol Immunol 2000, 189(1):19-26.

33. Huniche BS, Jensen LT, Birkelund S, Christiansen G: Mycoplasma contamination of Chlamydia pneumoniae isolates. Scand J Infect Dis 1998, 30(2):181-187.

34. Messmer TO, Black CM, Thacker WL: Mycoplasma contamination of chlamydiae isolated from clinical specimens. APMIS 1994, 102(10):793-796.

doi:10.1186/1756-0500-5-78

Cite this article as: Hwang et al:: A multi-laboratory profile of

Mycoplasma contamination in Lawsonia intracellularis cultures. BMC

Research Notes 2012 5:78.

\section{Submit your next manuscript to BioMed Central and take full advantage of:}

- Convenient online submission

- Thorough peer review

- No space constraints or color figure charges

- Immediate publication on acceptance

- Inclusion in PubMed, CAS, Scopus and Google Scholar

- Research which is freely available for redistribution

Submit your manuscript at www.biomedcentral.com/submit
Biomed Central 